\title{
DESAFIOS DA COMPLEXIDADE E DIMENSÃO SISTÊMICA DA RESPONSABILIDADE CIVIL
}

\section{Keila Pacheco Ferreira ${ }^{1}$}

Resumo: O manancial jurídico utilizado no ultrapassado paradigma da modernidade, especialmente no tocante à responsabilidade civil, não está totalmente apto a regular os desafios do terceiro milênio. Contingências e riscos nunca antes visitados acabam por compelir à busca por novas soluções, o que indica a inevitabilidade de uma transição paradigmática e gestão reconstrutiva da hermenêutica jurídica.

Palavras-chave: Complexidade; Responsabilidade civil; Sustentabilidade; Precaução; Riscos.

\section{COMPLEXITY CHALLENGES AND SYSTEMIC DIMENSION OF CIVIL LIABILITY}

Abstract: The legal source used in the overcome paradigm of modernity, especially with regard to civil liability, is not fully able to regulate the challenges of the third millennium. Contingencies and risks never before visited end up compelling the search for new solutions, which indicates the inevitability of a paradigm transition and reconstructive management of the legal hermeneutics.

Keywords: Complexity; Civil liability; Sustainability; Precaution; Risks.

\section{INTRODUÇÃO}

O manancial jurídico utilizado no ultrapassado paradigma da modernidade, especialmente no tocante à responsabilidade civil, não está totalmente apto a regular os desafios do terceiro milênio. Contingências e riscos nunca antes visitados acabam por compelir à busca por novas soluções, eclodindo o que Boaventura de Sousa Santos (2002, p. 48) denomina "crise da consciência especular", quando os espelhos sociais - como o direito, a educação, a informação, a religião e a tradição -, deixam de refletir a realidade vivida, período que, analisado sob uma perspectiva crítica, indica a inevitabilidade de

\footnotetext{
${ }^{1}$ Professora Adjunta da Faculdade de Direito da Universidade Federal de Uberlândia. Professora permanente e coordenadora do Programa de Pós-Graduação em Direito da Universidade Federal de Uberlândia. Doutora em Direito Civil pela Universidade de São Paulo. Mestre em Direito das Relações Sociais pela Pontifícia Universidade Católica de São Paulo. Líder do grupo de pesquisa Solidariedade, Sustentabilidade e Direitos Fundamentais. Endereço eletrônico: keilapacheco@ufu.br
} 
uma transição paradigmática e gestão reconstrutiva da hermenêutica jurídica.

Com efeito, é necessário repensar os instrumentos do Direito para a efetividade do controle de riscos (NOIVILLE, 2003, p. 217), o que implica na remodelação de um conjunto de construções jurídico-normativas tradicionais que vigoraram por mais de um século de positivismo jurídico, e na admissão da fragmentação da responsabilidade civil para a ressignificação dessa instituição que, diante dos desafios propostos na atualidade, acaba desacreditada em seus fundamentos e objetivos. Para tanto, a assunção de uma dimensão sistêmica pela responsabilidade civil é capaz de ensaiar um passo além do estabelecido, e construir um novo modelo, ao questionar a unicidade retrospectiva vigente, sobretudo ao considerar-se que "todas as crises iniciam com o obscurecimento de um paradigma e o consequente relaxamento das regras que orientam a pesquisa normal” (KUHN, 2000, p. 115).

Quando se observa, na sociedade, que a transformação dos modelos tecnocientífico e de produção trouxeram o incremento do risco como uma realidade, constata-se sem maiores dificuldades certa inadequação da responsabilidade civil reparatória para cuidar da vida social contemporânea e seus desdobramentos complexidade, contingência, reflexividade, consoante a constatação de Mathilde Boutonnet (2005, p.18): “o crescimento de catástrofes sanitárias e ecológicas, e as perspectivas para o campo da bioética, demonstram os limites da função reparatória. Há riscos e perigos que ameaçam o futuro da humanidade. (...) Não é necessário intervir antes que a reparação para impedir a realização de danos?” (tradução livre).

Contudo, recorda Eros Roberto Grau (2005, p. 384), que o Direito não atua apenas mediante leis, pois antes destas, convivendo e inteirando com as mesmas, existem valores e princípios, os primeiros, finalísticos, orientando teleologicamente, os segundos, deontológicos. Nesse horizonte, a absorção dos princípios da precaução e da prevenção nos domínios da responsabilidade civil é capaz de romper tradições, reorientar a função, revisitar os pressupostos e variar a aplicabilidade desse fundamental instituto na contemporaneidade.

Na sociedade atual, é necessário, pois, enfrentar os desafios da complexidade com visão poliocular, conforme adverte Edgar Morin (2005, p. 30), através de mecanismos redutores, entre os quais o sistema jurídico atua com primazia. A configuração da responsabilidade civil, portanto, necessita ser trabalhada no campo da multidisciplinaridade, justamente pelo fato de que deve ser compreendida como uma 
necessidade social, justificada em seu aspecto filosófico, para depois alcançar a dogmática jurídica.

Nesse passo, com o emprego do método de abordagem hipotético-dedutivo, reside o objetivo do presente artigo - perspectivar a dimensão sistêmica da responsabilidade civil como um novo ${ }^{2}$ modelo (REALE, 1994, p. 40) propositivo do direito obrigacional frente aos desafios da pós-modernidade, apto à tutela dos interesses desta e das futuras gerações.

\section{CRISE DA MODERNIDADE REFLEXIVA: A SOCIEDADE GLOBAL DE RISCO}

Na conhecida obra Risikogesellschaft, ${ }^{3}$ publicada na Alemanha em 1986, o sociólogo Ulrich Beck alertou para o fato de que a sociedade industrial da época moderna estava passando por transformações profundas que não resultavam de forças exteriores ao processo produtivo ou de revoluções sociais, mas constituíam-se o próprio reflexo da modernização simples ou industrial.

Por essa razão, esse processo foi compreendido como "modernização reflexiva" ou "segunda modernidade", na qual são evidenciadas as antinomias ou insuficiências da primeira modernidade ou, em outras palavras, a "era dos efeitos colaterais" (BECK; GIDDENS; LASH, 1997, p. 208), produtor de contingências incontroláveis que não podem ser abarcadas ou cobertas pelo cálculo do risco e do seguro, pois essas ameaças incalculáveis eliminam qualquer racionalidade instrumental e assinalam o retorno da incerteza.

Os riscos da modernidade reflexiva, impossíveis de bloquear, não constituem um evento apenas local ou limitado no tempo, ao contrário, o futuro é integrado ao presente e os riscos ultrapassam as fronteiras nacionais em intensa globalização. Os danos à natureza são socializados, o consumo cotidiano de itens indispensáveis, como comida,

\footnotetext{
${ }^{2}$ De plano, quadra advertir que a paulatina transição para este inovador modus operandi da responsabilidade civil não implica na substituição de sua lógica tradicional, que continuará atuante, entretanto, em seu campo específico de aplicação, pois "a passagem de uma fase para a outra não significa uma substituição radical da primeira pela segunda, significa apenas que um elemento se torna central em lugar de outro, o qual perde a própria hegemonia, mas não sua presença e influência” (MASI, 2003, p. 31).

3 Com tradução em língua portuguesa: BECK, Ulrich. Sociedade de risco: rumo a uma outra modernidade. Trad. Sebastião Nascimento. São Paulo: Ed. 34, 2010.
} 
água, medicamentos e utensílios domésticos escondem perigos os quais ninguém pode subtrair-se.

Vinte anos após, em 2007, Ulrich Beck publicou Weltrisikogesellschaft, ${ }^{4}$ obra que retoma a temática dos riscos para defender o conceito de uma sociedade global de risco. Durante as duas décadas posteriores à obra que inaugurou uma maneira singular de perceber a sociedade contemporânea, os riscos evidenciados pelo sociólogo alemão assumiram novas formas e significados, sendo que a publicação mais recente caracteriza, de certa forma, uma continuidade teórica do livro precedente, indicativo de novos quadros de referência.

Dentro dessa última análise, são enumerados três tipos de riscos globais, não exaustivos: os riscos de crises ecológicas - o cenário político foi forçado a reconhecer que as mudanças climáticas não resultam de mera especulação; os riscos de crises financeiras globais - que provocam efeitos mundiais de difícil controle; e o risco de ameaças terroristas - que se deslocaram para a arena global. Os dois primeiros, são riscos percebidos como colaterais ou acidentais, enquanto este último difere-se daqueles por ser intencional.

Diante da permanência da submissão ao risco pela sociedade globalizada, embora aquele possa assumir no tempo diversas tipologias, Ulrick Beck (2009, p. 30 et seq.) apresenta dois importantes conceitos, que alertam para uma atuação preventiva, o que ressalta o interesse do seu estudo para o presente ensaio.

O primeiro deles é a análise distintiva entre risco e catástrofe. Risco é a antecipação da catástrofe. O primeiro, não possui concretude espaço-temporal ou social; a segunda possui incidência no tempo e no espaço. Assim, de que forma o risco, que é um acontecimento futuro, pode ser antecipado, de forma a orientar as expectativas, ações, e forças políticas? A resposta do sociólogo é de que, através da encenação dos riscos globais, o futuro de catástrofes é percebido em tempo presente, com o objetivo de evitálas, o que demarca uma grande influência sobre decisões atuais.

O segundo, é a eliminação da distinção entre risco e a percepção cultural do risco. A concepção racionalista do risco trabalha com o risco objetivo, calculado e medido por especialistas, e a percepção cultural do risco ocorre em situações aonde há insuficiência de informações ou crenças antagônicas sobre os riscos. Beck defende que a

\footnotetext{
${ }^{4}$ A tradução em inglês foi publicada em 2009: BECK, Ulrich. World at risk. Translated by Ciaran Cronin. Cambridge: Polity Press, 2009.
} 
encenação do risco faz desaparecer a distinção entre realidade objetiva e percepção cultural, pois, não sendo o risco uma grandeza mensurável, a sua realidade reside justamente no caráter duvidoso. Assim, a exigência de um critério objetivo, segundo o qual o risco pode ser medido em graus, não leva em consideração que somente após uma determinada percepção é que os riscos são considerados urgentes e reais ou desprezíveis e fictícios. Disso decorre que saber se vivemos em um mundo objetivamente seguro não é fundamental, pois o que importa é que a encenação de riscos antecipados obrigue a uma ação.

Todos os elementos acima apontados indicam o conteúdo de uma nova dinâmica estrutural da sociedade no Século XXI - a sociedade global de risco, cujo norte reside na antecipação da catástrofe, capaz de alterar radicalmente o futuro da política global, o que Beck denomina "cosmopolitan material politics":

O mundo não é o que parece ser; enquanto sua existência e seu futuro dependem de decisões, decisões que desempenham aspectos positivos e negativos reciprocamente, que conectam o progresso e o declínio e que, como todas as coisas humanas, são portadoras de erro, ignorância, arrogância, promessa de controle e em última análise, até mesmo a semente de uma possível autodestruição. (2009, p. 04)

O risco, na semântica atual, revela duas faces - oportunidade e perigo, e essa ambivalência requer uma decisão que trata com incertezas e atua no domínio do provável e do plausível. Diante desse aspecto, os valores culturais influenciam fortemente a política preventiva ou precautória e a possibilidade de controle através de instrumentos jurídicos. Como exemplo, percebe-se que na Europa há o predomínio de medidas restritivas à utilização de alimentos geneticamente modificados (OGM), ao contrário dos Estados Unidos. Esse país, por sua vez, trata com exacerbado rigor os possíveis riscos decorrentes de terrorismo, o que não é percebido com tanta veemência em qualquer outra nação do mundo.

Portanto, a consciência e formas de gestão dos riscos estão estreitamente relacionadas às construções sociais, que podem empregar interpretações conflitantes, exageradas ou minimizadas, de acordo com interesses e pontos de vista diversos, como formas de expressão contemporânea de valores.

A percepção dos riscos de alcance global e o reconhecimento da condição de vulnerabilidade mundial, por sua vez, modifica o olhar sobre a sociedade e dá lugar a uma reconstrução em termos sociais, políticos, jurídicos, bem como origina um sentido ético 
conexo com a relação presente e futuro e a preservação da vida e humanidade: "é esse fato que torna a disputa em torno de medições, valores máximos aceitáveis e efeitos de curto e longo prazo, algo candente para a própria existência” (BECK, 2010, p.09).

Essa verificabilidade quanto à transformação do risco, projeta-se também como causa eficiente para a alteração de diversos institutos, para a inerente gestão, mitigação e prevenção, dentre eles a responsabilidade civil, que de uma visão centrada nos sujeitos e interesses individuais, passa a integrar um sistema que deve estar apto a lidar com conflitos policontextuais (TEUBNER, 2005), integrando aspectos econômicos, políticos, jurídicos, sociais, tecnológicos, científicos, teleológicos, entre outros, inaugurando, assim, uma dimensão sistêmica da responsabilidade civil, cuja diretriz é fornecida pelos princípios da precaução e da prevenção, conforme adiante será tratado no presente estudo. Ademais, há o redimensionamento da dignidade da pessoa humana e consequentemente, dos direitos personalíssimos, do direito à vida, do usufruto de propriedade e da saúde, de uma dimensão individualista em direção a um sentido transindividual, a fim de assegurálos de forma intrageracional (gerações presentes), e também intergeracional (futuras gerações).

Esse tempo compreendido como pós-moderno (LYOTARD, 1998, p. 100) traz ao debate contemporâneo o discurso sobre as regras que o legitimam, e consegue manter um discurso prospectivo a favor da humanidade, com o enaltecimento dos direitos humanos e defesa do meio ambiente. Contudo, não se desprende do globalismo (BECK, 1999, p. 211), que por sua vez, traz um aspecto puramente econômico, o que é um incessante problema atinente ao risco e à comercialização do risco.

Disso decorre a incerteza no quotidiano da sociedade e com ela a necessidade de meios para reduzir sua complexidade e precavê-la, pois o medo, de que nos fala Zygmunt Bauman (2008, p. 10), está umbilicalmente relacionado ao futuro.

Todos esses fatores demonstram a carência de uma ética que se renova, não no sentido do préstimo individual e caridoso, e sim justificados em novas fontes, particularmente na conjunção exposta por Edgar Morin (2007, p. 28), entre responsabilidade-solidariedade. De tal sorte, frente à sociedade global de riscos e diante da complexidade do equacionamento dos riscos admissíveis ou não, busca-se uma nova ética social e um novo sentido de responsabilidade, o que será exposto no capítulo a seguir. 


\section{2 - A RESPONSABILIDADE COMO DEVER DA ÉTICA CONTEMPORÂNEA}

Kant (1980, p. 101-102) constrói a sua fundamentação filosófica em três virtudes, que ainda hoje são condições indispensáveis ao fomento científico e à cognoscibilidade da sociedade e da humanidade. São elas: a física - a instância da natureza, a lógica - forma de conhecimento e, sobretudo, a ética como o mundo dos comportamentos humanos que, iniciando-se com preceitos altruísticos, como amor e amizade acabaram ao longo da jornada da civilização sendo matriz de diversas ciências e áreas da sociedade, nelas incluindo o Direito, a economia, a moral, a política, entre outras.

Assim, na dogmática da responsabilidade civil, o ethos fornece novo sentido, demonstrando hoje a insuficiência do modelo simplesmente retrospectivo, ou seja, reparatório, e abre campo para a função antecipatória da ocorrência de dano, sobretudo considerando certos danos não passíveis de serem sequer reparados ou compensados. Franz Wieacker (1983, p. 38), atento a essa dimensão, ao analisar a relação entre o direito privado e a sociedade industrial, reconhece que para a realização da justiça, o jurista deve reconhecer o ethos social, que na sociedade burguesa do século XIX correspondia à liberdade, sendo substituída, posteriormente, pela responsabilidade.

A evolução científica e tecnológica que levou o homem à sociedade global de riscos, pleno de certezas provisórias ou incertezas constantes, em incessante mutação, conferiu poderes de vida ou morte à humanidade contemporânea, em razão da amplitude espacial e temporal de suas ações. É justamente esse distanciamento entre as ações presentes e suas consequências futuras e a visão mecanicista amparada no ideal libertário, que em determinado momento contribuíram para que o homem não se sentisse responsável pelos efeitos dos seus atos, ausente qualquer sentimento de responsabilidade solidária.

A necessidade de gestão e controle do conhecimento gerado pela sociedade moderna estimulou a necessidade de uma abordagem ética acerca dos riscos sociais, para o estabelecimento de limites que, em outro momento, sejam materializados por instrumentos jurídicos, com um novo sentido de responsabilidade. Essa discussão, embora apresente dificuldades decorrentes do pluralismo de grupos sociais e da interdisciplinaridade de matérias, é caminho indispensável para a não realização de práticas que produzam consequências irreversíveis. 
Nessa trilha, diversos filósofos tomaram por objeto de investigação a intersecção entre ética e responsabilidade na sociedade contemporânea, cujos pensamentos centrais serão expostos a seguir.

Essa temática foi tratada por Edgard Morin (2007, p. 166) que propõe em seus estudos tanto a modificação das fontes da ética em nível individual como em nível planetário. Na primeira vertente, após transcorrer sobre a ética da honra, cujo fim é evitar pessoalmente as disfunções entre gestos e intenções, discorre quanto à ética da responsabilidade, na qual a autonomia do indivíduo tem necessária interface com a solidariedade, considerando que as situações desenvolvem-se em plexos comunitários. $\mathrm{Na}$ segunda vertente evidencia que o pertencimento de todos a esta Terra-Pátria faz emergir direitos e instâncias planetárias capazes de enfrentar problemas vitais, surgindo políticas de civilização que substituam modelos tão só de desenvolvimento, dando mostras efetivamente de um caminho que permita à humanidade chegar numa sociedademundo para além da idade de ferro planetária.

$\mathrm{O}$ desenvolvimento das ciências, de maneira geral, no século $\mathrm{XX}$ apontou problemas éticos decorrentes de múltiplos poderes de manipulação, o que impõe um controle político sobre novas técnicas e descobertas científicas. Para tanto, Morin (2006, p. 11) aponta a necessidade epistemológica de romper os limites do determinismo universal e simplificação, dogmas a serem ultrapassados, e absorver a probabilidade e a incerteza como medidas indispensáveis à captação da realidade. Por outras palavras, é necessário encaixar o conhecimento em um contexto global, sistemático, circular e dialógico, rejuntando fenômenos e rejeitando a causalidade linear, típica do pensamento clássico - este é o desafio da complexidade.

Rejeitando a ideia de que o pensamento complexo e o reconhecimento da incerteza (contradição entre o princípio do risco e o princípio da precaução) desencoraja a ação, Morin defende que com a força da participação, da solidariedade e da comunidade, a própria ação será corrigida para enfrentamento da incerteza, o que constitui um dos "sete saberes indispensáveis da educação do futuro":

Assim, a resposta às incertezas da ação é constituída pela escolha refletida de uma decisão, a consciência da aposta, a elaboração de uma estratégia que leve em conta as complexidades inerentes às próprias finalidades, que possa se modificar durante a ação em função dos imprevistos, informações, mudanças de contexto e que possa considerar o eventual torpedeamento da ação, que teria tomado uma 
direção nociva. (2000, p. 91)

Também François Ost (1995) alerta para uma redefinição ética, ao tratar da modificação das condições da ação humana, em um ambiente afetado qualitativamente por situações nunca antes observadas. De uma vivência passiva e condicionada ao acaso, as consequências coletivas virtualmente catastróficas passam a derivar do poder de ação do homem. Por essa razão, cada indivíduo, ao contribuir, mesmo que de forma infinitesimal, para efeitos globais de grande repercussão, atrai para si uma responsabilidade (ou corresponsabilidade) por uma ação coletiva cujas consequências ainda não são totalmente conhecidas.

O peculiar do pensamento de Ost é que ao trabalhar com uma responsabilidade compartilhada, amplia os mecanismos de responsabilização (solidariedade, objetivação) a um número cada vez mais vasto de pessoas. O domínio da ação ética, que classicamente se limitava à esfera das relações de intimidade e proximidade, no contexto da pósmodernidade sofre uma ampliação à escala universal. A responsabilidade estabelece um vínculo entre uma ação e suas consequências, mas ao contrário da configuração pretérita do tradicional pensamento ético e sua institucionalização jurídica (imputabilidade), a ideia de responsabilidade sofre um giro para o futuro, e assume uma tarefa de proteção, ou, nas palavras do jusfilósofo: “em lugar de procurar os culpados das ações passadas, ela serviria para definir o círculo das pessoas solidariamente investidas de novas missões" (1995, p. 309).

Essa responsabilidade voltada para adiante se refere à transmissão de um patrimônio da humanidade comum às gerações futuras (equidade intergeracional). Os conceitos principais desse modelo de responsabilidade são: responsabilidade-projeto (ao contrário de responsabilidade-imputação); gerações futuras como beneficiários; patrimônio (em dimensão alargada, referente ao meio, à natureza) e humanidade (linha virtualmente infinita).

Nesse ponto, interessa constatar que a concepção de Ost, ao tratar da proteção intergeracional, está diretamente vinculada com a aplicação do princípio da precaução, incentivando o necessário debate acerca da identificação e gestão de riscos e da tentativa de prever as possíveis consequências, com o objetivo de preservar o meio ambiente e o futuro da humanidade.

De igual sorte, Hans Jonas (2006) ressalta a necessidade de atuação sempre e de acordo com a permanência da vida humana, o que origina uma ética ecossocialista 
(responsável) para evitar que a destruição do meio ambiente não agrida as futuras gerações e nem mesmo a geração atual. Assim, rompendo com a ética tradicional, antropocêntrica, construída com base em direitos e obrigações e fundada na responsabilidade recíproca, a nova ética construída por esse filósofo é erguida em uma responsabilidade voltada para o futuro, fundamentada na globalidade do ser e no imperativo da existência, com fortes reflexos na crise ambiental e no risco tecnológico.

Dessa forma, crente na insuficiência dos imperativos éticos tradicionais diante das novas categorias do agir coletivo da civilização tecnológica, Jonas propõe o Princípio Responsabilidade como uma sistemática tentativa de fundamentar uma ética necessária às interferências sobre a natureza, pois as ações sob o signo da tecnologia possuem um alcance causal e abrangência espaço-temporal que carece de precedentes. Esse poder, até então inexistente, justifica a necessidade de uma ética que vai além do plano individual mas que norteia os atos também no âmbito coletivo e político.

Em tal linha, a ética proposta por Jonas ultrapassa a ética da intersubjetividade elaborada por Kant em seu conhecido imperativo categórico - "Age apenas segundo uma máxima tal que possas ao mesmo tempo querer que ela se torne uma lei universal" (1980, p. 129), e ao buscar uma ponderação sobre o significado da tecnologia sobre a condição moral do homem, elabora uma adaptação do imperativo kantiano - o "imperativo ético" -, vinculado a um novo tipo de ação humana: "Age de tal forma que os efeitos de tua ação sejam compatíveis com a permanência de uma autêntica vida humana sobre a terra" (JONAS, 2006, p. 47-48).

O Princípio Responsabilidade orienta-se, assim, por dois princípios, a "heurística do medo" e o "imperativo ético", ou seja, diante da incerteza e do risco tecnológico, a abordagem a ser observada é sempre de precaução (temor) e cautela (consciência no agir) pois as consequências da ação devem ser sempre avaliadas em função dos seus piores prognósticos. Em consequência, a responsabilidade corresponde a um critério ético que integra as gerações futuras, considerando que a perda da totalidade da vida pela ação se tornou uma possibilidade factível diante das intervenções negativas sobre a natureza.

Tomando-se em conta todos os elementos conceituais elaborados por Jonas, é possível sustentar que no âmbito jurídico, o princípio da precaução é fatalmente influenciado pela "heurística do medo", pois a prudência indica que na existência do risco, para que se evitem futuros danos, a melhor opção é sempre considerar o futuro mais 
pessimista. Igualmente, ao ressaltar a responsabilidade ética e o cuidado com as gerações futuras, o filósofo criou a base do que direito consolida como desenvolvimento sustentável.

Além dos filósofos anteriormente citados, pertinente ainda para a temática dos fundamentos éticos de uma função preventiva prospectiva da responsabilidade civil, ressaltar o pensamento de Paul Ricoeur (1995, p. 35 et seq), ao construir uma análise semântica do conceito de responsabilidade, para que os elementos imputação, solidariedade e risco assumam o lugar mais adequado dentro de uma "paisagem recomposta", qual seja, a realidade social e econômica do final do século XX.

A proposta de Ricoeur aproxima-se da de Jonas, ao tornar a responsabilidade o elemento principal da discussão ética da pós-modernidade. Contudo, ao passo que Jonas centraliza as suas preocupações sobre a descoberta da responsabilidade sobre a ação de alguém identificável que tenha causado um dano (imputação no sentido tradicional), Ricoeur sugere uma responsabilidade "social e coletiva" com orientação prospectiva, que tenha como norte a previsibilidade e avaliação das implicações da ação em relação ao futuro. Essa posição pode-se deduzir, dentre outras passagens significativas, do seguinte excerto de Ricoeur:

A orientação retrospectiva que a ideia moral de responsabilidade tinha em comum com a ideia jurídica, orientação em virtude da qual nós somos eminentemente responsáveis pelo que fizemos, deveria ser substituída por uma orientação mais deliberadamente prospectiva, em função da qual a ideia de prevenção dos prejuízos futuros se juntaria à de reparação dos danos já cometidos. Sobre esta ideia de prevenção tornar-se-ia possível reconstruir uma ideia de responsabilidade que desse resposta aos três motivos de inquietação antes invocados. ${ }^{5}$

No contexto do pensamento de Ricoeur, a responsabilidade civil deve perpassar um "deslocamento" do seu objeto, quer considerando que os riscos acabam sendo compartilhados entre seu causador e o vulnerável, quer considerando o distanciamento no tempo entre a ação prejudicial e os seus efeitos nocivos. Esse deslocamento visa à precaução, prevenção e prudência para a evitabilidade do dano.

A contribuição de Ricoeur para a responsabilidade civil contemporânea é indiscutível, já que torna possível a aplicação do conceito de responsabilidade em dupla

${ }^{5}$ RICOEUR, Paul. Op.cit., p.56. 
dimensão - retrospectiva e prospectiva, e traz novas perspectivas aos obstáculos encontrados na teoria da responsabilidade, ao tentar adaptar uma resposta dogmática clássica aos desafios trazidos pelo desenvolvimento tecnocientífico e sua inerente incerteza e riscos.

De todas as reflexões filosóficas expostas, é possível retirar elementos comuns que estabeleçam um mínimo ético, revelador de consenso, capaz de nortear o Direito. Desse exercício conclui-se que, diante da transformação ética da sociedade pós-moderna, em que a relação individual-intersubjetiva amplia-se para uma relação coletivaintergeracional, a ética da alteridade e a responsabilidade por outrem de que nos fala Levinas (2008, p. 74) alcança ampla dimensão. Nesse sentido, o termo responsabilidade reenvia a uma dimensão temporal - o futuro, no qual serão realizados os projetos comuns ao gênero humano.

Ao considerar-se que responsabilidade é não agir ao acaso, mas sim ter bem presente as consequências da ação, em um encadeamento entre liberdade limitada e previsão, é possível identificar na responsabilidade contemporânea um dever de comportamento (HELZEL, 2010, p. 29), qual seja, um dever de cuidado que é necessário manter em relação às consequências das próprias ações para com o outro, à coletividade e ao ambiente. Influenciada por uma nova ética, a responsabilidade se apresenta, assim, como um imperativo que obriga à reflexão sobre as consequências das ações, que dessa forma, guia e orienta o comportamento.

Esse fator reflete-se decisivamente na responsabilidade jurídica, pois já não é mais suficiente o simples desvio do dano da vítima para o agente: não se trata do tráfego ou logística do dano, particularmente considerando as potencialidades dos riscos existentes. Os danos devem ser evitados por imposição dos princípios da precaução e da prevenção para que não haja um fim da vítima ou da humanidade, mas exista sempre uma nova chance de começo.

Desenvolve-se, a partir dessas constatações, uma expectativa de reconfiguração do arsenal jurídico capaz de dar uma resposta satisfatória às necessidades de proteção e segurança atuais, a assumir novas funções, a descobrir novos recursos e reexaminar seus próprios fundamentos. Resta clara a importância, conforme apontam Nonet e Selznick (2010, p. 121 e126), de "tornar a lei mais responsiva às necessidades sociais":

[...] Uma instituição responsiva conserva a capacidade de compreender o que é essencial à sua integridade e ao mesmo tempo leva em consideração as novas forças do ambiente social. Para isso, ela se 
baseia nas formas pelas quais a integridade e a abertura se sustentam mutuamente, mesmo quando conflitantes. Percebe as pressões sociais como fontes de conhecimento e de oportunidades de autocorreção. Para assumir essa postura, a instituição necessita contar com a diretriz de uma finalidade. Os propósitos determinam padrões para a crítica da prática estabelecida, e com isso indicam direções para a mudança.

Ao se atribuir juridicidade ao valor ético da alteridade, encontra-se o ponto de intersecção entre a Filosofia e o Direito: a solidariedade, estabelecida pelo art. $3^{\circ}$ Constituição Federal de 1988 como objetivo da República Federativa do Brasil. Portanto, a solidariedade, no ordenamento jurídico brasileiro, não é apenas um valor, dependente do exercício da ética. Muito além disso, a solidariedade ganhou autoridade constitucional e deve atuar como vetor interpretativo e essência jurídica das ações estatais e privadas, e especificamente no tocante à dimensão sistêmica da responsabilidade civil, revela-se como um dos seus fundamentos jurídicos.

No que tange à seara ambiental, e já incorporando o substrato ético da responsabilidade contemporânea, Morato Leite e Ely Melo (2007, p.195-218) ressaltam o "princípio da responsabilização" para o enfrentamento dos problemas nesse domínio, exigindo-se a readaptação de alguns mecanismos da responsabilidade civil para fins de combate à degradação ambiental, através de uma configuração remodelada. Esse perfil, que tornaria a responsabilidade civil um sistema mais apto a trazer segurança à coletividade, inclui: a) a ampliação de funções do instituto, em que o caráter preventivo informado pelos princípios da precaução e da prevenção ganharia destaque, a par do caráter reparatório do dano; b) a inclusão da tutela preventiva de danos na esfera da responsabilidade civil como medida prioritária à reparação; c) a ausência de necessidade da efetiva concretização do dano, bastando a exposição da sociedade aos riscos; d) servir como garantia à conservação dos bens ambientais juridicamente protegidos.

Nessa versão, a responsabilidade civil não se ocupa apenas do passado, regressivamente, mas volta-se ao futuro, investida de novas missões. No tocante às gerações futuras, o princípio da precaução aponta o caminho para o reconhecimento de um conceito de justiça aberto à perspectiva intergeracional. Para tanto, Émilie Gaillard (2011, p. 337) destaca a necessidade de abstrair a noção de justiça do paradigma da reciprocidade, fundado na ideia de contato social entre pessoas, impossível de ser verificado quando houver distância temporal. A ultrapassagem desse paradigma implica o reconhecimento de que deve ser garantido aos sucessores da humanidade atual o acesso 
suficiente aos recursos que possam lhes suprir as mesmas necessidades essenciais das gerações presentes. Cria-se um novo pacto social de dimensões temporais locais e globais, que se coloca de maneira aberta à humanidade presente e futura, e para além disso, à proteção da vida como um valor em si mesmo.

A consagração desse "direito das gerações futuras", portanto, está fundamentado em dois elementos - o princípio da não discriminação temporal e o princípio da dignidade das gerações futuras, o que abre a possibilidade de recepção, pelos civilistas, de um conceito de responsabilidade intergeracional (GAILLARD, 2011, p. 353). Essa recepção de tutela das gerações futuras pelo Direito privado, especialmente através da responsabilidade civil, não passou despercebida aos olhos da doutrina brasileira. Com efeito, Cláudia Lima Marques e Bruno Miragem perceberam que:

No novo direito privado, tanto a noção de tutela do interesse das futuras gerações, quanto a responsabilidade decorrente de sua atuação surgem - ainda que em estágio inicial - do desenvolvimento do princípio da precaução e seus efeitos, bem como sobre a possibilidade e conveniência de sua proteção autônoma em relação aos titulares atuais de direitos [...] Essa proteção é reconhecida em diversas relações jurídicas de direito privado, relaciona-se atualmente com a bioética e as novas formas de fecundação in vitro e a preservação de embriões pro futuro; ou ainda a identificação de novos riscos e/ou danos futuros e sua contemplação pelo instituto da responsabilidade civil, especialmente no direito ambiental. (2012, p. 166-167).

Assim, o princípio da precaução ultrapassa uma lógica individualista e patrimonialista, que concebe o ambiente como propriedade a ser desfrutada, e aprofunda uma visão humanista, holística e solidarista que estimula a sensibilização para uma ética coletiva e universal.

\section{A INSUFICIÊNCIA DA FUNÇÃO REPARATÓRIA E O ESTABELECIMENTO DE UMA FUNÇÃO PREVENTIVA PROSPECTIVA DA RESPONSABILIDADE CIVIL}

É possível constatar que a responsabilidade civil na atualidade perpassa uma situação de crise, seja porque determinados setores antes regulados por ela cederam frente à socialização dos riscos por mecanismos de securitização, seja porque o instituto passou a assumir funções heterogêneas.

Com essa visão, Cesare Salvi (2005, p. 310 e 322) dedica um capítulo de sua 
obra a estudar "Il paradosso della responsabilità civile: espansione e crisi", no qual aponta que a incerteza funcional se traduz em incerteza normativa e operativa, sem contudo, descartar que o destino da responsabilidade civil tende irreversivelmente a um processo de diversificação, situando entre opostos extremos a função solidarista prevalente no campo dos danos à pessoa, aonde atuam de forma privilegiada a responsabilidade objetiva e a securitização, e de outro, a revitalização das funções de prevenção e de punição, em uma pluralidade de modelos articulados de forma funcional e operativa.

Também destacando a crise que perpassa a responsabilidade civil, Francesco D. Busnelli e Salvatore Patti (2013, p. 148) fazem referência a "La parábola della responsabilità civile", para os quais o momento presente representa provavelmente o seu ápice. Isso porque, consideram os juristas italianos, a expansão das fronteiras da responsabilidade civil corresponde a uma máxima multiplicidade de funções e o máximo grau de erosão dos elementos estruturais da teoria geral da responsabilidade civil, do que resulta um quadro, de um lado, reconfortante, considerando-se a transformação da tradicional rigidez interpretativa e aplicativa das normas sobre responsabilidade civil, tornando o instituto um dos mais dúcteis de todo o Direito privado; e de outro lado, preocupante, tendo em vista a incoerência sistemática que atravessa a responsabilidade civil, seja no aspecto funcional, seja no estrutural.

Essa situação igualmente é evidenciada por diversos juristas no Brasil. Anderson Schreiber (2007, p. 05), por exemplo, destaca a "erosão dos filtros da reparação", quais sejam, o "ocaso da culpa" e a "flexibilização do nexo causal" como um choque entre velhas estruturas e novas funções assumidas pela responsabilidade civil. Em semelhante entendimento, Maria Celina Bodin de Moraes (2003, p. 24) destaca que a estrutura da responsabilidade civil converteu-se em um amálgama de funções atribuídas pela jurisprudência, que ainda carecem de sistematização doutrinária, sobretudo no tocante à indenização por dano moral. De igual forma, Judith Martins-Costa (2009, p. 147) salienta que a multiplicidade de funções da responsabilidade civil é hoje um grande problema, que decorre da tensão entre a plasticidade do instituto e as novas necessidades sociais, agregando funções diversas à tradicional função de restauração dos danos ilicitamente causados.

Sem descurar os fatos e os argumentos que evidenciam um olhar crítico sobre a expansão da responsabilidade civil atual, convém destacar as insuficiências da função exclusivamente reparatória no contexto pós-moderno. 
Inicialmente, deverão ser avaliados os altos custos e ineficiência do sistema judicial de reparação de danos, que englobam, além da indenização propriamente dita, também os honorários advocatícios, peritos, custas judiciais, entre outros. Um estudo mencionado por Markesinis, Deakin e Angus (2013, p. 4), com relação ao sistema inglês e com dados apontados pela Pearson Commission, indicam que para arcar com duzentas mil libras de indenização, o custo administrativo era de cento e setenta e cinco mil libras. Embora referido estudo seja datado de 1978 e refira-se ao contexto britânico, essa realidade não parece tão apartada dos sistemas de civil law, tampouco do ambiente brasileiro, cuja morosidade percebida pelo senso comum do jurisdicionado é capaz de indicar, à míngua de um estudo estatístico apurado para diagnosticar a questão, que grande parte do numerário destinado ao ajuizamento de uma ação de indenização não é levado ao benefício da vítima.

Diante disso, a preocupação com a vítima e a necessidade de que a indenização tenha um percurso célere, fez com que as propostas de substituição ou complementação da responsabilidade civil com mecanismos de seguridade social ou seguro de responsabilidade civil alcançassem ampla adesão.

De outro lado, determinadas categorias de danos são capazes de demonstrar a falácia do retorno ao status quo ante.

Com efeito, restituir a vítima ao estado anterior ao dano, restabelecendo o equilíbrio social, é exigência natural de justiça comutativa, cuja observação remonta à ética aristotélica. Para tanto, informado pelo Princípio da Reparação Integral, o sistema de responsabilidade civil reparatório ex post dano trabalha com duas categorias: a da reparação natural, em que se busca restituir à vítima o exato bem sobre o qual incidiu o prejuízo, colocando-a o mais próximo possível da situação que antecedeu a ocorrência do dano, seja através da recomposição pela mesma coisa danificada ou sua substituição por outra; e o da indenização pecuniária, entregando à vítima um valor em dinheiro correspondente aos danos sofridos pela mesma. A primazia de uma ou outra categoria de reparação depende da opção e tradição de cada ordenamento jurídico.

No Brasil, a reparação in natura é incentivada em determinadas situações, como por exemplo, na esfera do Direito ambiental - arts. $4^{\circ}$, VI e VII e art. $14, \S 1^{\circ}$ da Lei 6.938/81; art. 225, $\S 2^{\circ}$ e $\S 3^{\circ}$, da Constituição Federal, e ainda arts. $3^{\circ}$ e 11 da Lei 7.347/85 -, tendo em vista que a melhor lição ambiental sustenta que "a reparação concreta do meio ambiente degradado é sempre preferível ao pagamento de indenização" (LEMOS, 
2010, p. 209). Convém observar que até mesmo quando a reparação é pecuniária, fixada em decorrência de ação civil pública, conforme previsão do art. 13 da Lei 7.347/85, o seu montante é destinado ao estabelecimento de um fundo especial, e os recursos destinados ao restabelecimento dos bens lesados, em privilégio da reparação natural.

Embora por força do disposto no art. 947 do Código Civil seja reservado um espaço para a reparação in natura no Direito brasileiro, de outro lado, quando houver extrema dificuldade ou impossibilidade de se reparar de forma específica, prevalecerá o sistema de indenização em dinheiro, cuja quantificação na atuação jurisdicional deve observar o disposto no art. 944 do Código Civil. Assim, tratando-se de indenização pecuniária, esta deve ser equivalente ao total do dano ocasionado. Referido dispositivo legal guarda o conteúdo expresso no Princípio da Reparação Integral e sua extensão, identificada por suas três funções fundamentais - compensatória, indenitária e concretizadora (SANSEVERINO, 2010, p. 58).

É inegável que o ordenamento jurídico brasileiro, assim como grande parte dos sistemas jurídicos estrangeiros (VINEY; JOURDAIN; 2010, p. 154), prestigia como proeminente a função reparatória da responsabilidade civil e o seu princípio correspondente, ao assegurar, na medida do possível, uma relação de equivalência entre a indenização e o dano sofrido. Corolário dessa posição é a não permissibilidade de métodos de tarifação abstrata de indenização, deixando a cargo do magistrado, diante das circunstâncias de fato evidenciadas, o estabelecimento do quantum debeatur.

O Princípio da Reparação Integral também atua, ainda, repelindo que a indenização seja caracterizada como fonte de enriquecimento sem causa (art. 884, Código Civil), afastando, a priori, o estabelecimento de uma função punitiva nos moldes da punitive damages típica do regime de torts do Direito anglo-americano. Sob essa ótica, a função reparatória da responsabilidade civil também é confrontada em decorrência da admissão desse instituto como mecanismo de salvaguarda aos valores essenciais das pessoas, o seu bem-estar, a qualidade de vida e o desenvolvimento das potencialidades humanas. Nessa conotação, a noção jurídica de dano abandona o sentido marcadamente patrimonial, e passa a ser concebido também como violação aos interesses que decorrem da personalidade (HOFMEISTER, 2002, p. 90-91). Logo, frente à impossibilidade de reposição do bem violado ao seu estado anterior, o critério apontado pela teoria da diferença (Diferenztheorie) (ALVIM, 1980, p. 214) para fixação da indenização por danos foi ultrapassado, e passou-se a admitir a função satisfatória da responsabilidade 
civil, que visa atribuir à vítima alguma compensação ou benefício de ordem material que possa contrabalançar o dano extrapatrimonial sofrido. Os danos verificados na esfera dos interesses imateriais também demonstram a insuficiência da função exclusivamente reparatória ao promover o desenvolvimento, sobretudo pela via jurisprudencial, de uma função punitivo-pedagógica com relação à fixação do montante da indenização, malgrado posicionamentos discordantes.

Convém explicitar que, mesmo entre aqueles que não admitem a adequação da função punitiva do dano moral no ordenamento jurídico brasileiro, hipóteses excepcionais de aplicação, taxativamente previstas em lei, devem ser consideradas, como no disposto no art. 13 da Lei ${ }^{\circ}$ 7.347/85, aplicável a situações potencialmente causadoras de danos a um universo coletivo ou difuso, como nas relações de consumo ou Direito ambiental, pois nesse caso, "a ratio será a função preventivo-precautória, que o caráter punitivo inegavelmente detém, em relação às dimensões do universo a ser protegido" (MORAES, 2003, p. 263). Trata-se do pagamento de uma multa a ser recolhida a um fundo público.

De outro lado, a dinâmica da vida pós-moderna e os novos modelos sociais decorrentes do desenvolvimento tecnocientífico e incremento do consumo, causadores de novos riscos à medida que inovadoras técnicas e produtos são disponibilizados, demonstram que a função reparatória não é suficiente, em inúmeras situações, para o restabelecimento da equivalência e justiça entre vítima e lesante, e principalmente, é falha ao garantir o alcance de segurança (na saúde, nos produtos de consumo, na alimentação, nos medicamentos, na preservação do meio ambiente, entre outros), tipicamente desejada pelas gerações humanas na contemporaneidade.

Os danos identificados na pós-modernidade apresentam traços peculiares, que os distinguem dos danos convencionais tratados pela responsabilidade civil reparatória, moldada como exigência de reação a um prejuízo que atingisse a esfera individual e patrimonial do indivíduo, o que impõe uma remodelação para lidar com as suas especificidades e conferir maior efetividade à responsabilidade civil.

Para esse entendimento, concorre a constatação de que a incerteza e irreversibilidade são elementos inerentes do dano na sociedade de risco. Nesse caso, Teresa Ancona Lopez avalia que "a função reparadora se esvazia diante do irreparável e essa constatação impulsiona a prevenção e a precaução como princípios da responsabilidade civil” (2010, p. 121).

De fato, vivencia-se, na sociedade contemporânea, uma categoria de danos que 
não se adequa perfeitamente à configuração clássica da responsabilidade civil, pois diversamente dos danos convencionais, que se verificam no plano intersubjetivo, os "novos danos" (especialmente com relação aos interesses da coletividade) se caracterizam de forma supra individual, podendo, de forma reflexiva, atingir direitos e bens individuais. Quanto aos "bens de incidência coletiva" (LORENZETTI, 2010, p. 23), a dificuldade em sua quantificação e apreciação econômica justifica a precedência da prevenção do dano, seguida da restituição, e somente não havendo êxito nestas possibilidades, buscar a reparação.

Além disso, há danos que decorrem de uma pluralidade de condutas, não havendo como determinar os seus autores através dos mecanismos causais clássicos de responsabilização. Importante, ainda, considerar que as manifestações de certos danos projetam-se no tempo e no espaço, o que dificulta a sua efetiva constatação e delimitação, bem como a identificação das gerações de vítimas, sejam elas presentes ou futuras (AYALA, 2010, p. 326-327). Essas peculiares características de danosidade, já identificadas pelas ciências sociais, demandam novos mecanismos de regulação jurídica, para que a eficácia de segurança e proteção que decorre das normas do Direito não esteja ameaçada.

Por todo o exposto, é forçoso concluir, na esteira das observações expostas por Viney e Jourdain (2010, p. 163) que o Princípio da Reparação Integral, informador da função reparatória da responsabilidade civil, embora apresente como vantagens a capacidade de modulação a situações particulares e seja perfeitamente adaptado aos danos patrimoniais, não é capaz de erigir-se como o único critério orientador dos magistrados para a avaliação de danos, devendo ser considerados também outros imperativos. Ao considerar perspectivas diversas que conduzem à atribuição de objetivos distintos da reparação como consequência da evolução da ideia de responsabilidade civil, os autores franceses enumeram: a utilização da responsabilidade civil como pena privada; a utilização do instituto como meio de prevenir a realização de danos que ameaçam se produzir, para os quais a ideia de reparação orientada ao passado seria insuficiente, bem como, ainda sob a ótica da prevenção, a utilização da responsabilidade civil orientada à gestão de riscos; e por fim, como reforços à eficácia da responsabilidade civil, anotam a utilização da função de restabelecimento à situação anterior ao dano e a função de cessação da ilicitude (VINEY; JOURDAIN, 2010, p. 4-42).

Todas essas transformações e tendências denotam que a função reparatória da 
responsabilidade civil deve ser relativizada, reconhecendo abertamente a vinculação axiológica expressada entre as funções da responsabilidade civil e a garantia de bens jurídicos fundamentais, individuais e coletivos. A proposta de interpretação da responsabilidade civil sob um viés preventivo é apoiada sobre a base do Estado Democrático de Direito, que melhor expressa um desideratum que uma realidade jurídico-positiva. Assim, ao mesmo tempo em que reflete a organização social, pretende transformar a realidade sob os influxos dos marcos constitucionais e aspiração popular, em especial com o fito de resguardar a fundamentalidade de direitos protegidos.

Com efeito, esse modelo estatal, plasmado no art. $1^{\circ}$ da Constituição Federal de 1988, erige-se sobre a base de direitos e garantias fundamentais que fixam premissas valorativas que devem inspirar toda a elaboração do Direito positivo e orientar a evolução dogmática da responsabilidade civil. De outro lado, a norma constitucional também enuncia deveres de proteção que afirmam a responsabilidade e vinculação jurídica à sua observância tanto do Poder Público como dos particulares, e enaltece a ideia de "responsabilidade comunitária dos indivíduos" e "auto responsabilidade na sua atuação social" (SARLET; FENSTERSEIFER; 2011, p. 134) não no sentido de uma responsabilidade apenas moral, mas sobretudo jurídica:

A caracterização do Estado Social e do conjunto de direitos fundamentais de segunda dimensão (sociais, econômicos e culturais) traz consigo a configuração de deveres sociais. Nesse cenário, é possível apontar, em termos gerais, para a criação de uma "consciência", um "ethos" jurídico-político de acordo com os quais o indivíduo existe para além da sua própria individualidade, caracterizando-se por ser um sujeito social responsável para com a existência comunitária à sua volta (ou seja, de todos os integrantes do grupo social) em patamares dignos. E tal responsabilidade não é apenas moral, mas também jurídica. (SARLET, FENSTERSEIFER, 2011, p. 136).

Em particular, a decisão dogmática básica, a saber, quais as funções assumidas pela responsabilidade civil atual, não podem ser compreendidas somente por leis ordinárias, senão fundadas nos cânones constitucionais do direito individual, coletivo e social de segurança - art. $5^{\circ}$, caput e art. $6^{\circ}$, caput; no objetivo fundamental e direitodever da solidariedade - art. $3^{\circ}$, inciso I; na existência humana digna - art. $1^{\circ}$, inciso III e art. 170, caput; na reparação de danos materiais e morais - art. $5^{\circ}$, inciso X, art. 225, parágrafo $3^{\circ}$, entre outros; e no dever de prevenção de danos atual e transgeracional - 
art. 225, caput. Ressaltando a prevenção de danos, pode-se, igualmente, destacar o princípio da inafastabilidade da jurisdição ou acesso à justiça - art. $5^{\circ}, \mathrm{XXXV}$, que acolheu a função preventiva da responsabilidade ao determinar que não se exclua de apreciação do Poder Judiciário lesão ou ameaça ao direito.

Uma vez fundada constitucionalmente as funções da responsabilidade civil, também a sua estruturação dogmática deve orientar-se, por óbvia conveniência, na base dos mesmos fundamentos constitucionais, pois a interpretação de seus pressupostos deve estar estabelecida conforme as funções que a Constituição permite atribuir à responsabilidade civil. A respeito, Rogério Donnini (2009, p. 493-494) expressa que "nossa Lei Maior recepcionou o princípio sub studio de maneira adequada e ampla, motivo pelo qual o dever de prevenção a danos e sua reparação tem incidência no sistema constitucional e, como consequência lógica, em todos os subsistemas dele decorrentes".

A responsabilidade civil há de encontrar, pois, seu fundamento nos princípios, objetivos, direitos, garantias e deveres constitucionais do Estado Democrático de Direito, que se converte assim no suporte valorativo dos pilares sobre os quais gravita todo o sistema teleológico da responsabilidade civil. Inegável, portanto, é reconhecer que a responsabilidade civil, além de reparar o dano, também cumpre uma função preventiva, o que é observado também por Manuel Carneiro da Frada (1994, p. 119):

[...] é função do Direito - e a observação pode fazer-se também em relação a outros sistemas - estabilizar e tutelar, no seu âmbito específico, as expectativas e condicionantes da existência dos homens por forma a subtraí-los do arbítrio destruidor da imprevisibilidade. [...] A contingência é assim inarredável e, se o sistema jurídico não pode eliminá-la, possui por outro lado meios para a prevenir ou controlar. [...] A responsabilidade civil comunga desta ratio que informa as normas jurídicas.

De observar-se, contudo, que a função preventiva da responsabilidade civil pode ser compreendida através de dois sentidos - o secundário e o primário.

No sentido secundário, a função preventiva traz a ideia de que a indenização imposta em decorrência do dano atua como elemento dissuasório, ou seja, poderoso incentivo para que o mesmo não se verifique novamente, presumindo um agir cauteloso do possível causador do dano para escapar à aplicação da sanção reparatória. Por sua vez, ao visualizar a responsabilidade civil sob a ótica da função preventiva, Luis Díez-Picazo (2011, p. 27) observa que "ao lado da prevenção como impulso psicológico aparece a 
prevenção como atividade racional do homo economicus", especialmente ao considerar os custos de segurança como um parâmetro para a eficiência.

Igualmente a já mencionada função punitiva da responsabilidade civil colabora para o alcance de um efeito preventivo secundário. Isto porque, a aplicação de uma indenização cujo valor ultrapasse a equivalência do dano causado, a par de caracterizar uma punição, também carrega um claro objetivo preventivo, através do que Paolo Gallo (1996, p. 167-169) denomina "função moralizadora dos danos punitivos".

O segundo sentido da função preventiva - o primário, por sua vez, sustenta que a responsabilidade civil pode atuar antecipadamente a ocorrência do dano para gestão e controle dos riscos, em um sentido preventivo prospectivo, voltado para o futuro. Essa abordagem se opõe radicalmente ao mecanismo tradicional de responsabilidade civil apoiado em uma conotação curativa e encontra fundamento nos princípios da precaução e da prevenção, que não poderiam restar indiferentes à responsabilidade civil, consoante ressalta Daphné Tapinos (2008, p. 20-21):

De fato, a proliferação e a extensão de alguns danos, em particular na área do meio ambiente e saúde, situaram o futuro da responsabilidade civil e a questão da adaptação dessa instituição aos fatos no centro das discussões. Não somente os riscos associados ao progresso constante da tecnologia contemporânea são mais numerosos, eles são atualmente menos tolerados pela sociedade. Sintoma da crescente preocupação com segurança, os princípios da prevenção e da precaução parecem cristalizar a crise, amplamente denunciada, que enfrenta atualmente o direito da responsabilidade civil.

Desta feita, cabe observar que o princípio tão caro à responsabilidade civil, alterum non laedere, pode perfeitamente ser compreendido como um atuar anterior à ocorrência do prejuízo, pois ordena precisamente não causar dano a outrem, incentivando tanto a prevenção ex ante, como também a reparação post factum (HERRERA, 2008, p. 201).

Privilegia-se, dessa forma, a coexistência social ordenada, ao abrigo de violações nas condições existenciais, sejam individuais ou difusas, atuais ou transgeracionais, sem descurar do aspecto protetivo que acompanha a responsabilidade civil, quando exprime um dever de garantia (STARCK, 1947, p. 43) em favor de todos os membros da sociedade ao contrapor liberdades e segurança. Ao considerar-se que o Princípio da Reparação Integral e o retorno ao status quo ante em sua totalidade é ficção, melhor adaptável aos danos patrimoniais, e de intrincada aplicação tanto aos danos difusos e 
coletivos quanto aos danos causados aos direitos da personalidade, o realce à função preventiva prospectiva da responsabilidade civil, que inclui o risco, a potencialidade do dano e a tutela preventiva como discussão prioritária, é tarefa que o ordenamento jurídico não apenas admite como incentiva. Em consequência, "a responsabilidade civil passa a se preocupar com as questões que estão por vir, todavia sem olvidar da necessidade de reparação dos danos já ocasionados" (LEITE; MELLO, 2007, p. 210).

\title{
CONCLUSÃO
}

\begin{abstract}
No hay un único principio de responsabilidad por daños, sino varios, y cada uno de ellos tiene su propio campo de aplicación. Es común a todos la idea de una justa compensación del daño o de un justo reparto de determinados riegos de daños. En esa medida todos ellos son principios del Derecho justo. (LARENZ, 1991, p. 125)
\end{abstract}

A concepção primeira da responsabilidade civil valia-se de modelo estruturado através de pressupostos invencíveis e subsequentes (conduta, nexo causal e dano) e de metodologia jurídica única, apta ao escopo de reparação (reflexo de visão patrimonialista), imprimindo para tanto assunção de perspectiva retrospectiva (ex post). No campo da teoria geral do direito, é perceptível que essa metodologia de escopo único tem origem no monismo normativista, onde o culto à norma se sobrepõe aos valores de justiça e solidariedade, impedindo o Direito, enquanto sistema jurídico, abrir-se em interdisciplinaridade e em ampla cognoscibilidade com as demais ciências (sociais, econômicas, políticas, biológicas, tecnológicas, informacionais etc.).

A partir da compreensão da responsabilidade civil como instituto voltado à proteção de bens e interesses atribuídos pelo Direito, não se justifica axiomaticamente a sua restrição ao escopo reparatório, mas um diálogo entre as variadas funções que teleologicamente encontram fundamento na Constituição Federal, para a promoção de valores voltados não apenas à vítima do dano, mas à proteção do gênero humano no contexto social, em legítima homenagem à solidariedade intergeracional.

Assim, as alterações de paradigmas, após as codificações primárias, para o advento do Estado Social, no campo da responsabilidade civil, foi protagonizado pela passagem do subjetivismo (na análise da culpa como a má utilização da liberdade) para o objetivismo (atividade que incute risco intolerável ou mediante especificações legais). Mesmo nesse novo ambiente, os esquemas de estrutura, dedução e análise retrospectiva 
não podem ser desprezados, já que permanecem úteis aos propósitos obrigacionais, quer na análise do caso concreto, quer no empréstimo de inerente experiência, inclusive jurisprudencial, a outros modelos de responsabilidade civil.

Observa-se, no entanto, o surgimento de uma reação jurídica para além da mera reparação, em verdadeiro giro metodológico, com a assunção de novos valores expressos em deveres e direitos fundamentais nas Constituições democráticas, bem como em normas de esfera infraconstitucional, que compreendem situações jurídicas subjetivas existenciais e de promoção ao hipervulnerável - as futuras gerações, essencialmente no aspecto difuso.

Corresponde à pós-modernidade, no âmbito da responsabilidade civil, a teoria da argumentação, oportunidade em que os princípios (no caso, da precaução e da prevenção) ganham projeção através da evitabilidade de danos geralmente irreversíveis, tanto do ponto de vista existencial presente ou futura, como da perspectiva patrimonial.

Neste caso, o que se busca é reconhecer maior densidade valorativa e eficácia normativa, bem como um caráter reestruturante do sistema, em que os princípios da precaução e da prevenção atuam justificando e expandindo o denso território normativo, dogmático e metodológico da responsabilidade civil, com o objetivo de reconhecer nos mesmos uma norma fundante e uma matriz estratégica que ordene a interpretação e a reconstrução teórica do instituto.

\section{REFERÊNCIAS}

ALTERINI, Atilio Anibal. Contornos actuales de la responsabilidade civil. Buenos Aires: Abeledo-Perrot, 1987.

ALVIM, Agostinho. Da inexecução das obrigações e suas consequências. 5 ed. São Paulo: Saraiva, 1980.

AYALA, Patrick de Araújo. A proteção jurídica das futuras gerações na sociedade de risco global. In: LEITE, José Rubens Morato; FERREIRA, Heline Sivini; BORATTI, Larissa Verri. Estado de direito ambiental: tendências. 2. Ed. Rio de Janeiro: Forense Universitária, 2010.

BAUMAN, Zygmun. Medo líquido. Trad. Carlos Alberto Medeiros. Rio de Janeiro: Jorge Zahar, 2008.

BECK, Ulrich. O que é globalização? Equívocos do globalismo: respostas à globalização. Trad. André Carone. São Paulo: Paz e Terra, 1999.

BECK, Ulrich. Sociedade de risco: rumo a uma outra modernidade. Trad. Sebastião Nascimento. São Paulo: Ed. 34, 2010. 
BECK, Ulrich. World at risk. Translated by Ciaran Cronin. Cambridge: Polity Press, 2009.

BOUTONNET, Mathilde. Le principe de précaution en droit de la responsabilité civile. Paris: L.G.D.J., 2005.

MARTINS-COSTA, Judith. Comentários ao novo Código Civil. Do inadimplemento das obrigações. Vol. V. Tomo II. $2^{\mathrm{a}}$ edição. Rio de Janeiro: Forense, 2009.

FRADA, Manuel Carneiro da. Contrato e deveres de proteção. Separata do volume XXXVIII do Suplemento ao Boletim da Faculdade de Direito da Universidade de Coimbra. Coimbra: Gráfica de Coimbra, 1994.

DONNINI, Rogério. Prevenção de danos e a extensão do princípio neminem laedere. In: NERY, Rosa Maria de Andrade e DONNINI, Rogério (Organizadores). Responsabilidade Civil: estudos em homenagem ao Professor Rui Geraldo Camargo Viana. São Paulo: Editora Revista dos Tribunais, 2009.

BUSNELLI, Francesco D.; PATTI, Salvatore. Danno e responsabilità civile. Terza Edizione. Torino: G. Giappichelli Editore, 2013.

DIEZ-PICAZO, Luis. Fundamentos del derecho civil patrimonial V: la responsabilidade civil extracontratual. Pamplona: Civitas-Thomson Reuters, 2011.

GAILLARD, Émilie. Générations futures et droit privé: vers un droit des generations futures. Paris: L.G.D.J, 2011

GRAU, Eros Roberto. O direito posto e o direito pressuposto. São Paulo: Malheiros, 2005.

HELZEL, Paola B. La nozione di responsabilità baricentro tra etica, diritto e politica. In: CALABRÓ, Gian Pietro (a cura di). La nozione di responsabilità tra teoria e prassi. Milano: CEDAM, 2010.

HERRERA, Edgardo López. La función preventiva de la responsabilidad civil y su relación con las otras funciones. Revista de derecho de daños 2008-2: prevención del dano. Dirigido por Jorge Mosset Iturraspe y Ricardo Luis Lorenzetti. Santa Fe: RubinzalCulzoni, 2008.

HOFMEISTER, Maria Alice Costa. O dano pessoal na sociedade de risco. Rio de Janeiro: Renovar, 2002.

IRTI, Natalino. Diritto Privato e società industriale. Trad. Gianfranco Liberati. Napoli: Edizione Scientifiche Italiane, 1983.

JONAS, Hans. O princípio responsabilidade: ensaio de uma ética para a civilização ecológica. Rio de Janeiro: Contraponto, Puc Rio, 2006.

KANT, Immanuel. Fundamentação da metafísica dos costumes. Trad. Paulo Quintela. São Paulo: Abril Cultural, 1980.

KUHN, Thomas S. A estrutura das revoluções científicas. $5^{\mathrm{a}}$ ed. São Paulo: Perspectiva, 2000.

SALVI, Cesare. La responsabilità civile. Milano: Dott. A. Giuffrè Editore, 2005.

LARENZ, Karl. Derecho justo: fundamentos de etica juridica. Traducción y presentación Luis Díez-Picazo. Madrid: Editorial Civitas, 1991. 
LEITE, José Rubens Morato; MELO, Melissa Ely. As funções preventivas e precaucionais da responsabilidade civil por danos ambientais. Revista Sequência, $\mathrm{n}^{\mathrm{o}} 55$, p.195-218, dez. 2007.

LEMOS, Patrícia Faga Iglecias. Direito ambiental: responsabilidade civil e proteção ao meio ambiente. 3. ed. rev., atual. e ampl. São Paulo: Editora Revista dos Tribunais, 2010.

LEVINAS, Emmanuel. Totalidade e Infinito, Coimbra: Edições 70, 2008.

LOPEZ, Teresa Ancona. Princípio da Precaução e Evolução da Responsabilidade Civil. São Paulo: Quartier Latin, 2010.

LORENZETTI, Ricardo Luis. Teoria geral do direito ambiental. Trad. Fábio Costa Morosini e Fernanda Nunes Barbosa. São Paulo: RT, 2010.

LYOTARD, Jean-François. O pós-moderno. $3^{\mathrm{a}}$ ed. Trad. Ricardo Corrêa Barbosa. Rio de Janeiro: José Olympio Editora, 1998.

MARQUES, Cláudia Lima; MIRAGEM, Bruno. O novo direito privado e a proteção dos vulneráveis. São Paulo: Editora Revista dos Tribunais, 2012.

MARKESINIS, Basil; DEAKIN, Simon; Angus, Johnston. Tort Law. Seventh edition. Oxford: Oxford University Press, 2013.

MASI, Domenico de. A sociedade pós-industrial. 4. ed. Trad. Anna Maria Capovilla. São Paulo: Senac, 2003.

MORAES, Maria Celina Bodin de. Danos à pessoa humana: uma leitura civilconstitucional por danos morais. Rio de Janeiro: Renovar, 2003.

MORIN, Edgar. O método 6: ética. Trad. Juremir Machado da Silva. Porto Alegre: Sulina, 2007.

MORIN, Edgard. Ciência com consciência. $8^{a}$ ed. Trad. Maria D. Alexandre e Maria Alice Sampaio Dória. Rio de Janeiro: Bertrand, 2005.

MORIN, Edgard. Complexidade e ética da solidariedade. In: CASTRO, Gustavo de; CARVALHO, Edgard de Assis; ALMEIDA, Maria da Conceição de. Ensaios de complexidade. $4^{\mathrm{a}}$ ed. Porto Alegre: Sulina, 2006.

MORIN, Edgard. Os sete saberes necessários à educação do futuro. $2^{\mathrm{a}} \mathrm{ed}$. Trad. Catarina Eleonora F. da Silva e Jeanne Sawaya. São Paulo: Cortez; Brasília, DF: UNESCO, 2000.

NOIVILLE, Christine. Du bon gouvernement des risques: le droit et la question du "risque acceptable". Paris: Presses Universitaires de France, 2003.

NONET, Philippe; SELZNICK Philip. Direito e sociedade: a transição ao sistema jurídico responsivo. Trad. Vera Ribeiro. Rio de Janeiro: Revan, 2010.

OST, François. A natureza à margem da lei: a ecologia à prova do direito. Lisboa: Instituto Piaget, 1995.

REALE, Miguel. Fontes e modelos do direito: para um novo paradigma hermenêutico. São Paulo: Saraiva, 1994.

RICOEUR, Paul. O justo ou a essência da justiça. Trad. Vasco Casimiro. Lisboa: Instituto Piaget, 1995.

SANSEVERINO, Paulo de Tarso Vieira. Princípio da reparação integral: indenização no Código Civil. São Paulo: Saraiva, 2010. 
SANTOS, Boaventura de Sousa. Para um novo senso comum: a ciência, o direito e a política na transição paradigmática. Vol. 1. A crítica da razão indolente: contra o desperdício da experiência. 4. ed. São Paulo: Cortez, 2002.

SARLET, Ingo Wolfgang; FENSTERSEIFER, Tiago. Direito Constitucional Ambiental: estudos sobre a Constituição, os Direitos Fundamentais e a Proteção do Ambiente. São Paulo: Editora Revista dos Tribunais, 2011.

SCHREIBER, Anderson. Novos paradigmas da responsabilidade civil: da erosão dos filtros da reparação à diluição dos danos. São Paulo: Atlas, 2007.

STARCK, Boris. Essai d'une théorie générale de la responsabilité civile considérée en sa double fonction de garantie et de peine privée. Paris: L. Rodstein, 1947.

TAPINOS, Daphnée. Prevention, precaution et responsabilité civile: risque avéré, risque suspecté et transformation du paradigme de la responsabilité civile. Paris: L'Harmattan, 2008.

TOFFLER, Alvin. O choque do futuro. Trad. Marco Aurélio de Moura Matos. Rio de Janeiro: Artenova, 1973.

VINEY, Geneviève; JOURDAIN, Patrice. Traité de Droit Civil: Les effets de la responsabilité. $3^{\mathrm{e}}$ éd. Paris: LGDJ, 2010. 